\title{
Coupling of Multiple Numerical Models to Simulate Electroslag Remelting Process for Alloy 718
}

\author{
Nils GIESSELMANN, ${ }^{1)}$ Antje RÜCKERT, ${ }^{1) *}$ Moritz EICKHOFF, ${ }^{1)}$ Herbert PFEIFER, ${ }^{11}$ Jürgen TEWES ${ }^{21}$ and \\ Jutta KLÖWER ${ }^{2)}$
}

1) RWTH Aachen University, Department for Industrial Furnaces and Heat Engineering, Kopernikusstraße 10, 52074 Aachen, Germany.

2) VDM Metals GmbH, Plettenberger Straße 2, 58791 Werdohl, Germany.

(Received on December 29, 2014; accepted on March 12, 2015)

\begin{abstract}
The Electroslag Remelting (ESR) process concerns the use of a consumable metal electrode, which is used to melt through a slag layer into a water-cooled mold by applying an alternating electric current. The ESR process produces large ingots of a high quality. This is achieved by controlled solidification and chemical refinement. An understanding of the solidification, heat and fluid flow in the ESR process is essential in order to predict the presence of defects in the solidified ingot. Due to the transient nature of the multiphase, non-isothermal fluid flow problem with magneto-hydrodynamic effects, melting and solidification modeling is a complex task.

This paper presents the combination of two coupled computational fluid dynamics (CFD) models to simulate both the fluid flow in the slag layer, including metal droplet formation, and solidification in the metal pool. The simulation has been performed for Alloy 718 and compared to experimental data. The presented $3 \mathrm{~d}$-model is able to simulate both the steady state and the transient ESR process.
\end{abstract}

KEY WORDS: ESR process; CFD; MHD; transient; Alloy 718.

\section{Introduction}

The electroslag remelting process is a remelting process with a consumable electrode. The process produces large ingots of higher quality than the original material by controlled solidification and chemical refinement. Alternating or direct current flows from the solid electrode through the slag layer and the metal pool to the bottom plate. Thereby Joule heat is generated in the molten slag, due to its electrical resistance. The heat is transferred to the electrode and the ingot and is removed via the water cooled mould. The material on the electrode tip is melted. Depending on the melting rate, this material passes through the slag layer, either as a droplet or a jet, and reaches the metal pool. Then the metal solidifies, due to the mould cooling, and forms an ingot with a high grade of directional solidification, depending on the heat balance. A thin solidified slag film develops on the ingot surface during the solidification. This film is responsible for an electrical and thermal insulation between ingot and mould. Furthermore an air gap forms between ingot and mould due to the shrinkage during solidification. There is a primary interest in quantifying the influence of certain process parameters on the structure and the chemical composition of the product. The fluid flow in the slag and in the metal pool has a big influence on macrosegregation and the local solidification time. The fluid flow is driven by buoyancy forces, droplet motion and Lorentz force. Figure 1

\footnotetext{
* Corresponding author: E-mail: arueckert@iob.rwth-aachen.de DOI: http://dx.doi.org/10.2355/isijinternational.55.1408
}

shows the principle design of an ESR plant. ${ }^{1)}$

This paper presents a 3d-model suitable for both steady state and transient ESR simulation. This is achieved by coupling different models and two different simulation codes.

A lot of research has been done concerning the simulation of ESR processes. In the 1980 s Choudhary ${ }^{2}$ developed the first models combining Maxwell's equations, fluid flow and heat transfer for ESR systems. Choudhary first attempted to no longer postulate the pool profile instead he actually

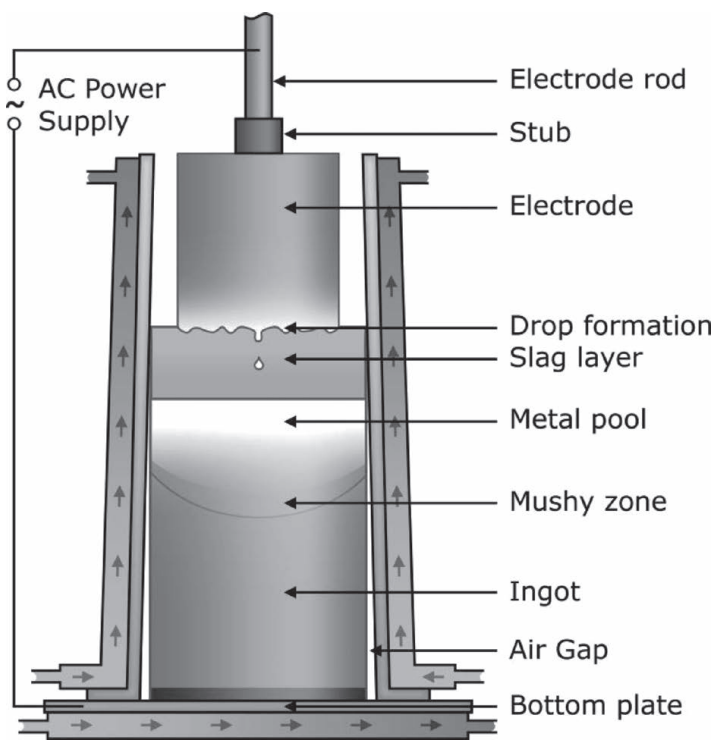

Fig. 1. Principal scheme of an ESR Plant. 
computed it. Celafu ${ }^{3)}$ goes a step further by taking solute transport into account to consider solutal buoyancy effects on fluid flow, the aim being to determine factors that affect macrosegregation. Jardy ${ }^{4}$ investigated Rayleigh number distributions as a criterion to characterize the freckling tendency of the ingot. Based on this, Jardy tried to find an optimum melt rate to achieve the lowest possible Rayleigh numbers. Mitchell ${ }^{5-7)}$ did extensive work on ESR simulation, including inhomogeneous heat transfer to the mould, different solidification mechanisms and even process parameter fluctuation. However, drop formation and the motion of metal drops through the slag layer has usually been neglected or simplified, except in recent work by Kharicha. ${ }^{8)}$ Kharicha investigates metal droplet behavior using multiphase fluid flow simulation, but does not relate the information gained concerning metal droplets and flow in the slag to the solidification in the metal pool. Using this information as an input quantity for solidification simulation seems to be a reasonable approach and is pursued in this paper.

\section{Numerical Model}

In order to simulate the electroslag remelting process accurately a variety of phenomena have to be taken into account. Heat transfer has to be computed in the entire computational domain and through its boundaries. Fluid flow phenomena have to be considered in the liquid slag layer and the liquid metal pool which interacts with the solidifying metal. During the droplet formation magneto hydrodynamic effects also should be considered. The finite volume method (FV) is appropriate for solving multiphase fluid flow and heat transfer, as it is a conservative method. The magnetic Reynolds numbers are rather low, therefore electromagnetic phenomena occurring during the melting process can be solved more efficiently using the finite element method (FE). Using a loose coupling scheme and combining these two methods seems to be a reasonable approach, in agreement with Hübner ${ }^{9)}$ and Masse. ${ }^{10)}$ Besides droplet formation and detaching of metal droplets during the whole process needs to be simulated using a fine grid and a very small timescale. In contrast the transient simulation of solidification and heat transfer can be solved using time steps about three magnitudes larger. Summarizing, a combination of different models, each offering specific advantages and avoiding the limitations, seems to make sense for efficient ESR simulation.

\subsection{Fluid Dynamics}

The fluid dynamics are solved using a finite-volume approach. The mathematical description of fluid flow is based on the equation of continuity (1) and momentum (2).

$$
\begin{aligned}
& \frac{\partial \rho}{\partial \mathrm{t}}+\nabla \cdot(\rho \cdot \overline{\mathrm{v}})=\mathrm{S}_{\mathrm{m}} \ldots \ldots \ldots \ldots \ldots \ldots \ldots \ldots \ldots \ldots \ldots \ldots \ldots \ldots \ldots \\
& \frac{\partial}{\partial \mathrm{t}}(\rho \cdot \overline{\mathrm{v}})+\nabla \cdot(\rho \cdot \overline{\mathrm{v}} \cdot \overline{\mathrm{v}})=-\nabla \mathrm{p}+\nabla \cdot(\bar{\tau})+\rho \cdot \overline{\mathrm{g}}+\overline{\mathrm{F}} \ldots \\
& \rho: \text { Density } \\
& \mathrm{t}: \text { Time } \\
& \overline{\mathrm{v}}: \text { Velocity vector } \\
& \mathrm{S}_{\mathrm{m}}: \text { Volume specific mass source }
\end{aligned}
$$

p: Pressure

$\overline{\bar{\tau}}$ : Shear stress tensor

$\overline{\mathrm{g}}$ : Gravity

$\overline{\mathrm{F}}$ : Volume specific force vector

The shear stress tensor $\overline{\bar{\tau}}$ can be described using the dynamic viscosity and the velocity field as shown in Eq. (3).

$$
\bar{\tau}=\mu_{\mathrm{D}}\left(\left(\nabla \overline{\mathrm{v}}+\nabla \overline{\mathrm{v}}^{\mathrm{T}}\right)-\frac{2}{3} \nabla \cdot(\overline{\mathrm{v}} \cdot \overline{\overline{\mathrm{e}}})\right)
$$

$\mu_{\mathrm{D}}$ : Dynamic viscosity

$\overline{\overline{\mathrm{e}}}$ : Unity tensor

The realizable $\mathrm{k}-\varepsilon$ model has been chosen to model the turbulence in the fluid region. Therefore the energy Eq. (4) employs effective quantities.

$$
\begin{aligned}
& \frac{\partial}{\partial \mathrm{t}}(\rho \cdot \mathrm{e})+\nabla \cdot(\overline{\mathrm{v}} \cdot(\rho \mathrm{e}+\mathrm{p}))= \\
& \nabla \cdot\left(\lambda_{\mathrm{eff}} \cdot \nabla \mathrm{T}+\bar{\tau}_{\text {eff }} \cdot \overline{\mathrm{v}}\right)+\mathrm{S}_{\mathrm{e}}
\end{aligned}
$$

e: Internal energy

$\lambda_{\text {eff: }}$ Effective thermal conductivity

T: Temperature

$\overline{\bar{\tau}}_{\text {eff }}:$ Effective shear stress tensor

$\mathrm{S}_{\mathrm{e}}$ : Volume specific energy source

In the case of the metal-slag simulation the volume of fluid (VoF) technique has been chosen to resolve the two phase fluid flow. The VoF model makes use of a single set of momentum equations but solves these for each phase's volume fraction in a continuity Eq. (5). Considering a two phase flow, only one phase's volume fraction is required. The complementary fraction can be computed easily, as the sum of all volume fractions needs to equal unity as shown in Eq. (6). The interphase is tracked using a piecewise linear interface reconstruction scheme that keeps the phase boundary sharp.

$$
\begin{array}{r}
\frac{1}{\rho_{\mathrm{i}}} \cdot\left(\frac{\partial}{\partial \mathrm{t}}\left(\alpha_{\mathrm{i}} \cdot \rho_{\mathrm{i}}\right)+\nabla \cdot\left(\alpha_{\mathrm{i}} \cdot \rho_{\mathrm{i}} \cdot \overline{\mathrm{v}}\right)\right)=0 \\
\sum_{\mathrm{i}=1}^{\mathrm{n}_{\text {Species }}} \mathrm{a}_{\mathrm{i}}=1 \ldots \ldots \ldots \ldots \ldots \ldots \ldots \ldots \ldots \ldots \ldots \ldots \ldots
\end{array}
$$

$\rho_{\mathrm{i}}$ : Density of species $\mathrm{i}$

$\alpha_{\mathrm{i}}$ : Volume fraction of species $\mathrm{i}$

\subsection{Electromagnetics}

Electromagnetics can be considered using Maxwell's equations. These consist of a combination of the following equations: Faraday's law (7), Ohm's law (8) and Ampère's law (9).

$$
\begin{gathered}
\nabla \times \overline{\mathrm{E}}=-\frac{\partial \overline{\mathrm{B}}}{\partial \mathrm{t}} \ldots \\
\overline{\mathbf{J}}=\sigma(\overline{\mathrm{E}}+\overline{\mathrm{V}} \times \overline{\mathrm{B}}) \\
\overline{\mathbf{J}}=\nabla \times \frac{1}{\mu} \overline{\mathrm{B}} \ldots
\end{gathered}
$$

$\overline{\mathrm{E}}$ : Electrical field

$\overline{\mathrm{B}}$ : Magnetic flux

$\overline{\mathrm{J}}$ : Current density

$\sigma$ : Electric conductivity 
$\mu$ : Magnetic permeability

Both, the magnetic flux and the current density, represent conservative quantities, therefore their divergence needs to be equal to zero, Eqs. (10) and (11).

$$
\begin{aligned}
& \nabla \cdot \overline{\mathrm{J}}=0 \\
& \nabla \cdot \overline{\mathrm{B}}=0
\end{aligned}
$$

Furthermore the magnetic vector potential is being introduced in Eq. (12). By definition its curl equals the magnetic flux. This definition directly satisfies the conservation of the magnetic flux. The magnetic vector potential is being used to unite Maxwell's equations into one Eq. (13).

$$
\begin{array}{r}
\overline{\mathrm{B}}=\nabla \times \overline{\mathrm{E}} \\
\nabla \times \frac{1}{\mu} \nabla \times \overline{\mathrm{E}}+\sigma \frac{\partial \overline{\mathrm{E}}}{\partial \mathrm{t}}=\sigma(\overline{\mathrm{v}} \times \nabla \times \overline{\mathrm{E}}-\nabla \phi)
\end{array}
$$

\section{$\overline{\mathrm{E}}$ : Electrical field}

$\phi$ : Electric potential

Because of low magnetic Reynolds numbers and considering an alternating current the electromagnetic equations can be solved in a harmonic manner. Therefore the real and imaginary quantities are introduced. The resulting parameters, Lorentz force density and Joule heating distribution, can be obtained using Eqs. (14) and (15). These quantities are required in the momentum and heat transfer equation respectively.

This leads to the following set of equations to compute the Lorentz force density and the Joule heat.

$$
\begin{gathered}
\overline{\mathrm{F}}_{\mathrm{V}, \mathrm{L}}=\frac{1}{2}\left(\mathrm{~J}_{\mathrm{r}} \mathrm{B}_{\mathrm{r}}+\mathrm{J}_{\mathrm{i}} \mathrm{B}_{\mathrm{i}}\right) \\
\dot{\mathrm{q}}^{\prime \prime \prime}=\frac{1}{2}\left(\mathrm{~J}_{\mathrm{r}} \mathrm{E}_{\mathrm{r}}+\mathrm{J}_{\mathrm{i}} \mathrm{E}_{\mathrm{i}}\right) .
\end{gathered}
$$

$\overline{\mathrm{F}}_{\mathrm{V}, \mathrm{L}}$ : Volume specific Lorentz force

$\mathrm{J}_{\mathrm{r}}$ : Real part of the current density

$\mathrm{J}_{\mathrm{i}}$ : Imaginary part of the current density

$\mathrm{B}_{\mathrm{r}}$ : Real part of the magnetic flux

$\mathrm{B}_{\mathrm{i}}$ : Imaginary part of the magnetic flux

$E_{\mathrm{r}}$ : Real part of the electric field

$\mathrm{E}_{\mathrm{i}}$ : Imaginary part of the electric field

$\dot{\mathrm{q}}^{\prime \prime \prime}$ : Volume specific heat flux

The present model assumes an electrically insulating skin of slag. Therefore the magnetic flux needs to be parallel to the computational domain boundaries on the top, side and bottom surface. This is realized by constraining the magnetic vector potential to zero on these boundaries.

\subsection{Droplet Simulation}

The numerical model used to describe the transient motion in the slag region and also the metal droplet formation requires a coupling of fluid dynamics and electromagnetics. Two segregated solvers have been chosen, ANSYS FLUENT and ANSYS EMAG. Not all variables need to be transferred between the two codes at each time step. On the one hand, because of low magnetic Reynolds numbers, only either the metal or the slag phase distribution needs to be transferred to the electromagnetic solver. On the other hand, only the Joule heat and Lorentz force distribution are required for the fluid dynamic solver. Therefore the communication bandwidth between both solvers can be kept to a low level.

This model is being used to obtain time averaged quantities in the slag region that are used to describe the slag behavior in the solidification model. Time averaging is required for the variables velocities, turbulent kinetic energy, dissipation, Joule heat, Lorentz force and especially the metal droplet positions. ANSYS FLUENT computes the phase's volume fraction in each cell that directly correlates to the electrical resistivity.

\subsection{Mushy Region}

The enthalpy porosity technique is being used to describe the fluid flow in the mushy region. It was shown by Poirier ${ }^{11)}$ that the inter dendritic flow follows Darcy's law, Eq. (16).

$$
\nabla \mathrm{p}=-\frac{\mu_{\mathrm{D}}}{\mathrm{K}} \overline{\mathrm{v}}
$$

\section{K: Permeability}

The enthalpy porosity technique uses the so called mushy zone constant to describe the ratio between viscosity and permeability, Eq. (17). The mushy zone constant should therefore be chosen carefully.

$$
\frac{\mu_{\mathrm{D}}}{\mathrm{K}}=\frac{\left(1-\mathrm{f}_{\mathrm{liq}}\right)^{2}}{\mathrm{f}_{\mathrm{liq}}{ }^{3}+0.001} \cdot \mathrm{A}_{\text {mush }}
$$

\section{$f_{\text {liq }}$ : Liquid fraction}

Amush: Mushy zone constant

In this manner both velocities and turbulence quantities are lowered crucially in the mushy region. The mushy zone constant has been determined by calculating the fluid flow around the dendrites.

ANSYS FLUENT assumes a linear correlation between temperature and liquid fraction between solidus and liquidus temperature that is not valid for Alloy 718. Therefore a Scheil-Gulliver based approach has been chosen to calculate the liquid fraction in dependence of temperature. In this manner solidus temperature is reached at $1338 \mathrm{~K}$, which is rather low compared to Pottlacher et al., ${ }^{12)}$ but should be appropriate due to micro segregation phenomena. The liquid fraction with respect to temperature is presented in Fig. 2.

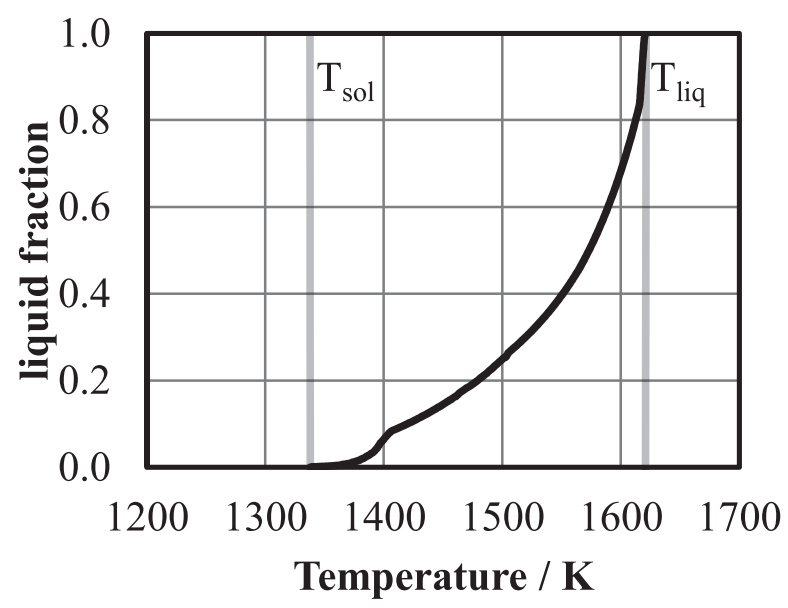

Fig. 2. Liquid fraction with respect to temperature. 


\subsection{Thermal Stresses}

During solidification and further down cooling the material starts to shrink. Therefore a gap is formed between the metal and the copper mold. In order to appropriately model this gap thermal stresses need to be taken into account in the metal. Assuming an axisymmetric behavior the elastic strains will be computed using Eq. (18).

$$
\begin{aligned}
& \varepsilon_{\mathrm{r}}=\frac{\partial \mathrm{w}_{\mathrm{r}}}{\partial \mathrm{r}} ; \quad \varepsilon_{\varphi}=\frac{\mathrm{W}_{\mathrm{r}}}{\mathrm{r}} ; \\
& \varepsilon_{\mathrm{z}}=\frac{\partial \mathrm{w}_{\mathrm{z}}}{\partial \mathrm{z}} ; \quad \varepsilon_{\mathrm{rz}}=\frac{1}{2}\left(\frac{\partial \mathrm{w}_{\mathrm{z}}}{\partial \mathrm{r}}+\frac{\partial \mathrm{w}_{\mathrm{r}}}{\partial \mathrm{z}}\right)
\end{aligned}
$$

$\varepsilon_{\mathrm{r}}: \quad$ Radial strain

$\varepsilon_{\phi}:$ Tangential strain

$\varepsilon_{\mathrm{z}}:$ Axial strain

$\varepsilon_{\mathrm{rz}}:$ Shear strain

$\mathrm{w}_{\mathrm{r}}$ : Radial displacement

$\mathrm{W}_{\mathrm{Z}}$ : Axial displacement

The stresses are calculated as function of the strains, Young's modulus, Poisson's ratio and the thermal shrinkage as shown.

$$
\begin{aligned}
& \sigma_{\mathrm{r}}=\frac{(1-v) \mathrm{E}}{(1+v)(1-2 v)}\left[\varepsilon_{\mathrm{r}}+\frac{v}{1-v}\left(\varepsilon_{\varphi}+\varepsilon_{\mathrm{z}}\right)-\frac{1+v}{1-v} \alpha_{\mathrm{T}} \mathrm{T}\right] \\
& \sigma_{\varphi}=\frac{(1-v) \mathrm{E}}{(1+v)(1-2 v)}\left[\varepsilon_{\varphi}+\frac{v}{1-v}\left(\varepsilon_{\mathrm{r}}+\varepsilon_{\mathrm{z}}\right)-\frac{1+v}{1-v} \alpha_{\mathrm{T}} \mathrm{T}\right] \\
& \sigma_{\mathrm{z}}=\frac{(1-v) \mathrm{E}}{(1+v)(1-2 v)}\left[\varepsilon_{\mathrm{z}}+\frac{v}{1-v}\left(\varepsilon_{\varphi}+\varepsilon_{\mathrm{r}}\right)-\frac{1+v}{1-v} \alpha_{\mathrm{T}} \mathrm{T}\right] \\
& \sigma_{\mathrm{zr}}=\frac{\mathrm{E}}{(1+v)} \varepsilon_{\mathrm{zr}}
\end{aligned}
$$

$$
\begin{aligned}
\sigma_{\mathrm{r}}: & \text { Radial stress } \\
\sigma_{\phi}: & \text { Tangential stress } \\
\sigma_{\mathrm{z}}: & \text { Axial stress } \\
\sigma_{\mathrm{rz}}: & \text { Shear stress } \\
v: & \text { Poisson's ratio } \\
\alpha_{\mathrm{T}}: & \text { Thermal expansion coefficient }
\end{aligned}
$$

The computational domain is divided into several elements that need to satisfy the equilibrium of forces according to Eq. (20).

$$
\begin{aligned}
& \frac{\partial \sigma_{\mathrm{r}}}{\partial \mathrm{r}}+\frac{\partial \sigma_{\mathrm{rz}}}{\partial \mathrm{z}}+\frac{1}{\mathrm{r}}\left(\sigma_{\mathrm{r}}-\sigma_{\varphi}\right)=0 \\
& \frac{\partial \sigma_{\mathrm{rz}}}{\partial \mathrm{r}}+\frac{1}{\mathrm{r}} \sigma_{\mathrm{rz}}+\frac{\partial \sigma_{\mathrm{z}}}{\partial \mathrm{z}}=0
\end{aligned}
$$

This approach has been implemented in a MATLAB code that has been validated by comparing the results to those of an ANSYS FEM model. This thermal stress model can be used to calculate the size of the air gap at all axial positions for a given temperature distribution. As the air gap affects the temperature field, this computation also needs to be coupled to the fluid dynamics solver.

\subsection{Zonal Model}

Handling solidification of industrial size ingots requires rather large time steps compared to those used to describe the droplet behavior. The ESR simulation is divided into different zones, in order to handle different time scales for multiphase flow and thermal equilibrium. Looking at the metal droplet formation and multiphase fluid flow in the slag region, a transient simulation with the "Volume of Fluid" technique is being used that requires very small time steps within the order of milliseconds. The shape of the mushy region is determined as a function of the temperature distribution in the ingot and metal pool. Thermal equilibrium is achieved in the order of thousand seconds and can even be computed in a steady state simulation.

A scheme of the different zones is presented in Fig. 3. One model (zone 1) handles the multiphase flow and magneto hydro dynamics (MHD) on a fine time and length scale. The time averaged results, including fluid flow, turbulence quantities, metal droplet positions and Joule heating distribution, are being transferred to a steady simulation (combination of zone 2 and 3). The phase boundary slag-metal pool (between zone 2 and 3 ) needs to be modeled in a steady manner to ensure the numerical stability for larger time steps. This can be achieved by a combination of symmetry boundary conditions on the phase boundary an d additional user defined source terms that handle heat flux, shear stress and turbulence transport perpendicular to the phase boundary. The source terms can be calculated using Eq. (21) and by inserting the quantities listed in Table $\mathbf{1}$.

$$
\mathrm{S}_{\xi, \mathrm{m}}=2 \cdot \frac{\xi_{\mathrm{s}}-\xi_{\mathrm{m}}}{\mathrm{dx}_{\mathrm{z}}^{2} \cdot\left(\frac{1}{\Gamma_{\mathrm{s}}}+\frac{1}{\Gamma_{\mathrm{m}}}\right)}
$$

$\mathrm{S}_{\xi, \mathrm{m}}$ : Volume specific source term in the metal

$\xi_{\mathrm{s}}$ : Flow variable in the slag

$\xi_{\mathrm{m}}$ : Flow variable in the metal

$\mathrm{dx}_{\mathrm{z}}$ : Cell length in $\mathrm{z}$-Direction

$\Gamma_{\mathrm{s}}$ : Effective diffusivity in the slag

$\Gamma_{\mathrm{m}}$ : Effective diffusivity in the metal

Equation (21) describes the diffusive transport through the phase boundary. These source terms have been validated against a fully coupled Volume of Fluid simulation. The

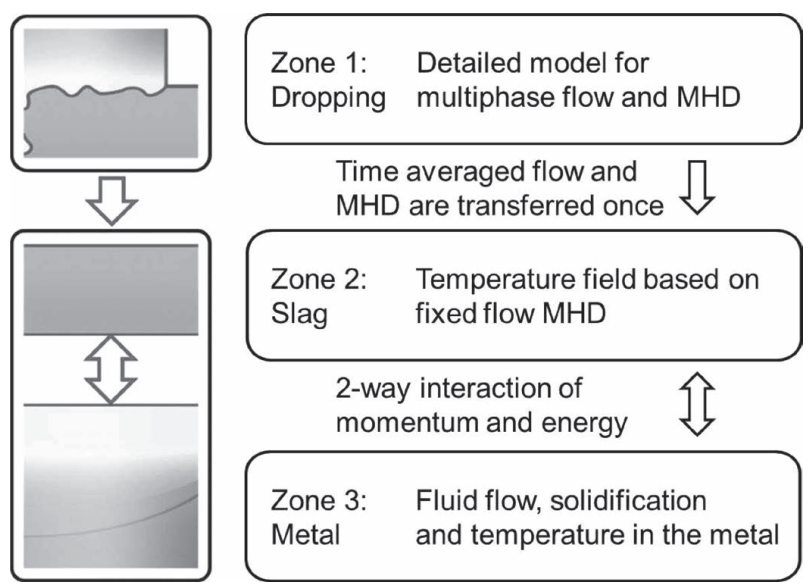

Fig. 3. Combination of different zones to simulate the ESR process. 
separate calculation of the droplet simulation and the solidification reduces the calculation time significantly.

\section{Results}

\subsection{Droplet Simulation}

Simulations of the metal droplet behavior in the slag region have been carried out for laboratory scale and industrial scale ingots. Modelling the industrial scale plants requires a computationally expensive three dimensional simulation. Previous studies ${ }^{1)}$ have shown that a $2 \mathrm{D}$ axisymmetric model is suitable for the laboratory scale plant. The plant geometry and the numerical model parameters are listed in Table 2.

The fluid flow and velocity distribution for the $500 \mathrm{~mm}$

Table 1. Source term quantities.

\begin{tabular}{ccccc}
\hline & Heat flux & Shear stress & $\mathrm{k}$ & $\varepsilon$ \\
\hline $\mathrm{S}_{\xi}$ & $\dot{\mathrm{q}}^{\prime \prime \prime}$ & $\mathrm{F}_{\mathrm{r}}$ & $\mathrm{k}_{\mathrm{v}}$ & $\varepsilon_{\mathrm{v}}$ \\
$\xi$ & $\mathrm{T}$ & $\mathrm{v}_{\mathrm{r}}$ & $\mathrm{k}$ & $\varepsilon$ \\
$\Gamma$ & $\lambda_{1}+\lambda_{\mathrm{t}}$ & $\mu_{1}+\mu_{\mathrm{t}}$ & $\mu_{1}+\frac{\mu_{\mathrm{t}}}{\sigma_{\mathrm{k}}}$ & $\mu_{1}+\frac{\mu_{\mathrm{t}}}{\sigma_{\varepsilon}}$ \\
\hline
\end{tabular}

Table 2. Geometry and model parameters.

\begin{tabular}{lcc}
\hline & Case a & Case b \\
\hline Electrode diameter & $0.110 \mathrm{~m}$ & $0.420 \mathrm{~m}$ \\
Mold diameter & $0.150 \mathrm{~m}$ & $0.500 \mathrm{~m}$ \\
Slag height & $0.095 \mathrm{~m}$ & $0.200 \mathrm{~m}$ \\
Model dimensions & 2D axisymmetric & $3 \mathrm{D}$ \\
Cell spacing & $0.5 \mathrm{~mm}$ & $2.2 \mathrm{~mm}$ \\
Cell count & $64 \cdot 10^{3}$ & $2.1 \cdot 10^{6}$ \\
Time step size & $0.001 \mathrm{~s}$ & $0.01 \mathrm{~s}$ \\
Simulated time & $70 \mathrm{~s}$ & $85 \mathrm{~s}$ \\
Number of cores (FLUENT/EMAG) & $6 / 6$ & $6 / 6$ \\
CPU time & $21.4 \mathrm{hours}$ & $12.2 \mathrm{days}$ \\
\hline
\end{tabular}

mold are presented in Fig. 4. One metal droplet is currently passing through the slag near the centerline. The bottom surface of the electrode shows a lot of droplets evolving over a large part of the electrode's area. The high Lorentz force density near the electrode edges causes the slag flow to point inwards near the electrode. Then the fluid flow moves downwards below the electrode, outwards near the metal pool and rises near the copper mould. In total the slag presents a similar flow field to that simulated for the laboratory scale plant.

The droplet distribution for both cases is presented in Fig. 5. It can be shown that in the case of the laboratory scale electrode droplets only occur on the axis of symmetry, while looking at the $420 \mathrm{~mm}$ electrode droplets detach over a large fraction of the electrode radius. Nevertheless, no droplets arise near the electrode edges as the Lorentz force driven slag flow pushes the molten metal a certain distance to the centerline.

\subsection{Solidification}

Besides the refining process that takes place near the slag, the prediction of the solidification behavior is among the top priorities of remelting simulations. Furthermore validating the numerical model is only possible by investigations of the solidified ingot. Validation is being achieved by considering

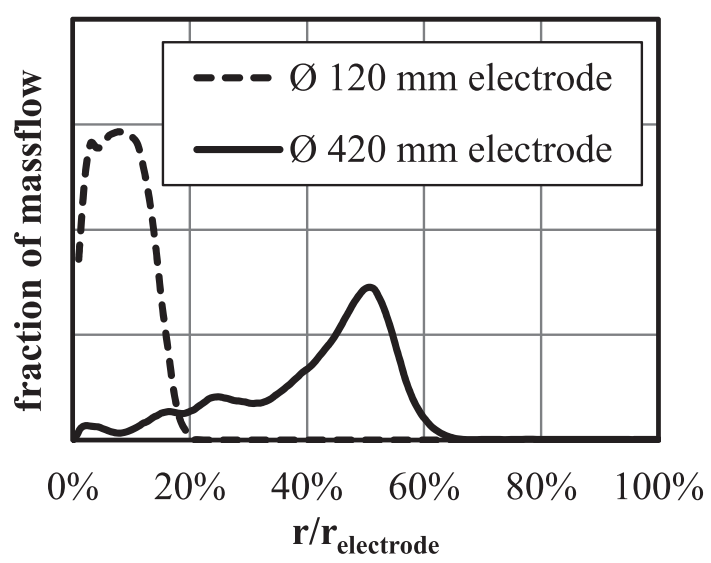

Fig. 5. Droplet positions for two electrode dimensions.

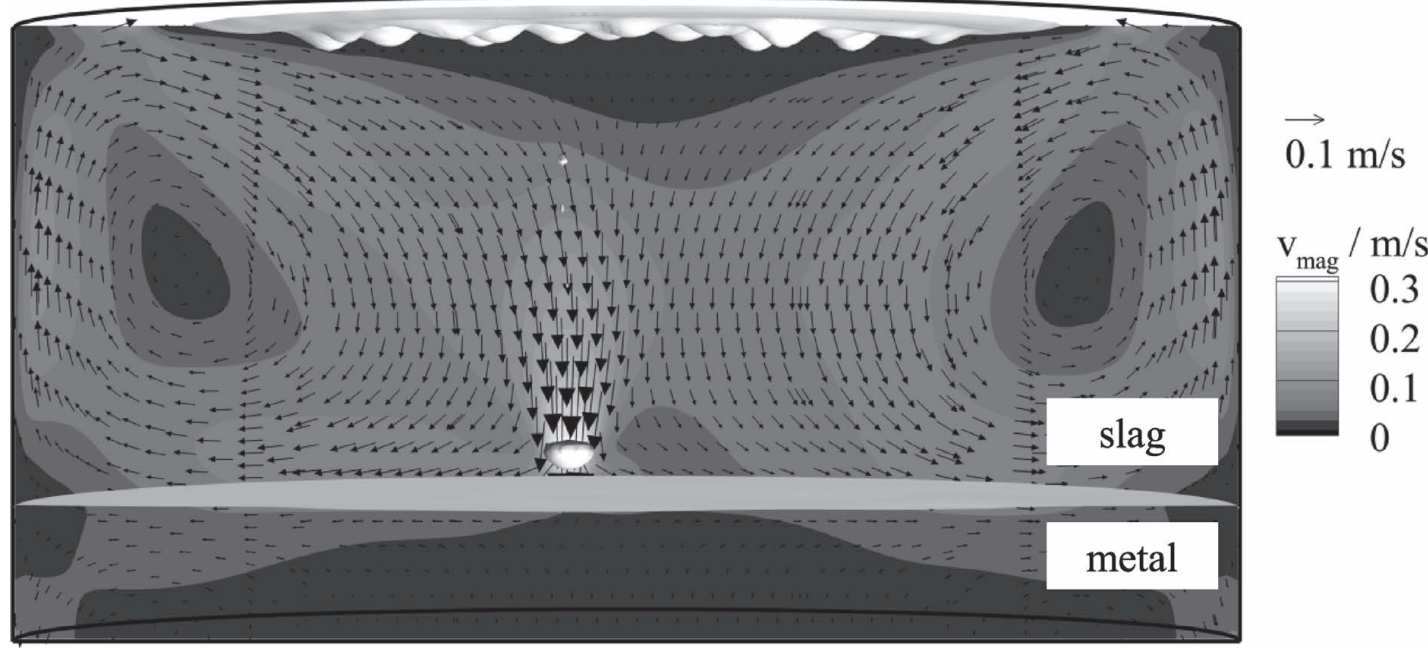

Fig. 4. Fluid flow and velocity distribution for a $500 \mathrm{~mm}$ mold. 


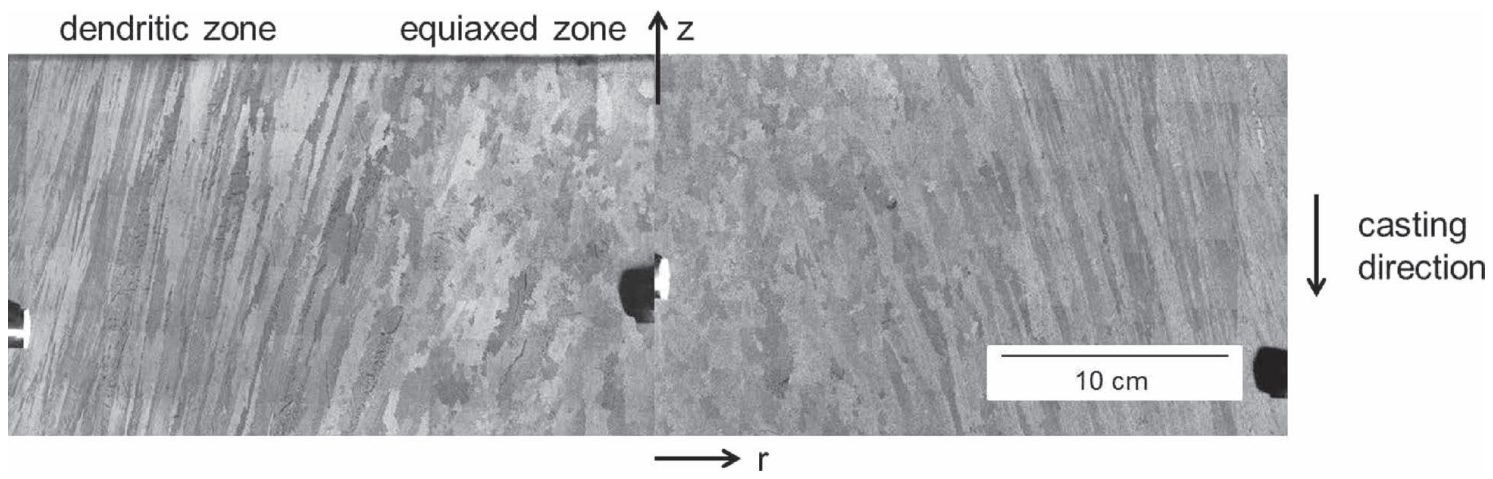

Fig. 6. Polished and etched slice from the $500 \mathrm{~mm}$ ingot.

a)

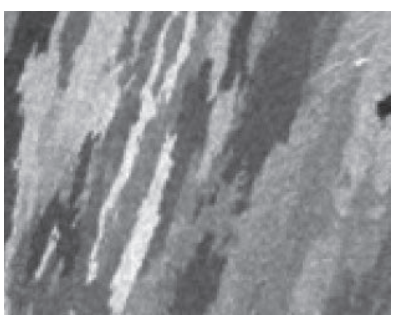

c)
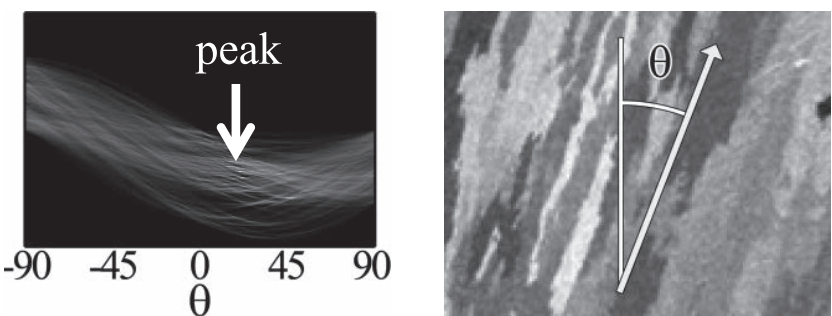

Fig. 7. Grain orientation detection scheme: a) Image section; b) Canny edge detection; c) Hough transformation - peak at $\theta=21^{\circ}$; d) Derived grain orientation.

the grain orientation as well as the secondary dendrite arm spacing using polished and etched slices from the ingot, Fig. 6.

The grain orientation is being examined using macroscopic images of the slices. The analysis is performed according to an automated scheme. The steps are illustrated in Fig. 7. After selecting a subsection of the sample, the grain boundaries are detected using a Canny approach. ${ }^{13)}$ This is followed by a Hough transformation to detect the dominant orientation. The Hough transformation represents a commonly used technique for edge orientation detection that has been proven to be very robust. ${ }^{14-16)}$

The pool profiles obtained represent the liquidus lines at different times. The secondary dendrite arm spacing (SDAS) is another criteria for the solidification. The SDAS is measured at many different radial positions on the slice. Nastac et al. ${ }^{17)}$ published a relation between SDAS and the local solidification time (LST), Eq. (22). The LST can easily be examined in the simulation and therefore be compared to experimental data.

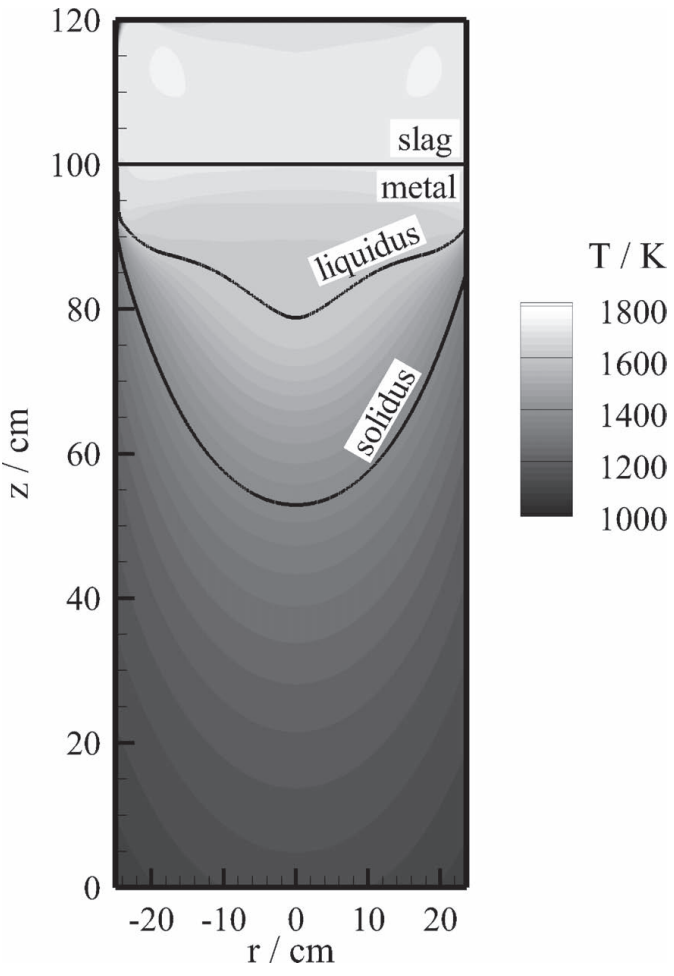

Fig. 8. Simulated temperature distribution (case b).

$$
\mathrm{SDAS}=\mathrm{c}_{\mathrm{SDAS}} \cdot\left(\frac{\mathrm{LST}}{1 \cdot \mathrm{S}}\right)^{\mathrm{eSDAS}}
$$

$\mathrm{c}_{\text {SDAS }}$ : empirical prefactor $\left(9.67 \cdot 10^{-6}\right)$

esDAs: empirical exponent $(1 / 3)$

Figure 8 shows the temperature distribution for case b. As expected, the highest temperatures are to be found in the slag layer a few centimeters below the electrodes edges, while the slag right beneath the electrode is slightly cooler. The metal pool appears very hot at the top, but a rapid change in temperature occurs at $\mathrm{z}=0.92 \mathrm{~m}$. This jump is caused by the increasing density of alloy 718 even before the solidification begins, which inhibits the mixing of the fluid in the metal pool. The temperature gradient in the metal is very high before the air gap forms at $\mathrm{z}=0.84 \mathrm{~m}$ and starts to decrease afterwards. Furthermore the distance between the isothermal lines of liquidus and solidus is small at the corners and large at the centerline.

The simulations for both ingot diameters are compared to optically determined pool profiles. The liquidus isothermals 
for both cases are presented in Fig. 9. Case b shows an equiaxed zone in the ingot center, therefore the pool profile can only examined for $\mathrm{r}<0.1 \mathrm{~m}$. In both cases the numerical model agrees reasonably well with the experimentally gained data. The slope of the isothermal is fairly similar in most parts of the radius. However, the simulation predicts a slightly steeper pool at the outer part of the ingot in case b.

For case b with the $\varnothing 500 \mathrm{~mm}$ mould the SDAS is presented in Fig. 10. The experimentally measured SDAS demonstrates a standard deviation to the extent of about 30 $\mu \mathrm{m}$ in the ingot center. The standard deviation decreases towards larger radial coordinates. The numerical simulation results show a very similar slope compared to that of the measured pool profile and SDAS values within the range of the measured data's standard deviation. Still, the SDAS that are calculated using Nastac's empirical formula based on the numerical model are always slightly lower than the measured ones.

Summarizing much effort has been done to validate the numerical results and the agreement with experimental data is quite satisfying.

\section{Conclusions}

In this paper the development of a simulation strategy is presented, which enables a detailed description of relevant regions to appropriately model the electroslag remelting process. One of the challenges is to ensure a sufficient efficiency of the numerical model so that it can be used to perform extensive parametric studies. This is achieved by combining multiple computational domains and coupling the simulation codes ANSYS FLUENT and ANSYS EMAG. Therefore the electroslag remelting process is divided into a droplet simulation and models that account for the fluid flow in the slag and fluid flow and solidification in the metal pool.

The droplet simulation considers the multiphase flow and the interaction of fluid flow and magneto hydrodynamics to simulate the behavior of the metal droplets passing through the slag layer. The Lorentz force is the main driving force for the fluid flow established in the slag region, which causes the liquid metal film on the bottom surface of the electrode to be transported to the centerline. Therefore it was found that no metal droplets detach near the electrode edge. Instead the droplets accumulate at a certain characteristic radius. Between this radius and the centerline metal droplets form and detach homogeneously. In the case of the laboratory scale remelting plant, metal droplets only occur on the centerline.

The steady state simulation of the electroslag remelting process introduces a static phase boundary, which separates the slag and the metal region. It could be shown that the use of a symmetry boundary condition, which is combined with additional terms that take in account momentum and heat transfer through this boundary, appropriately models the
Case a

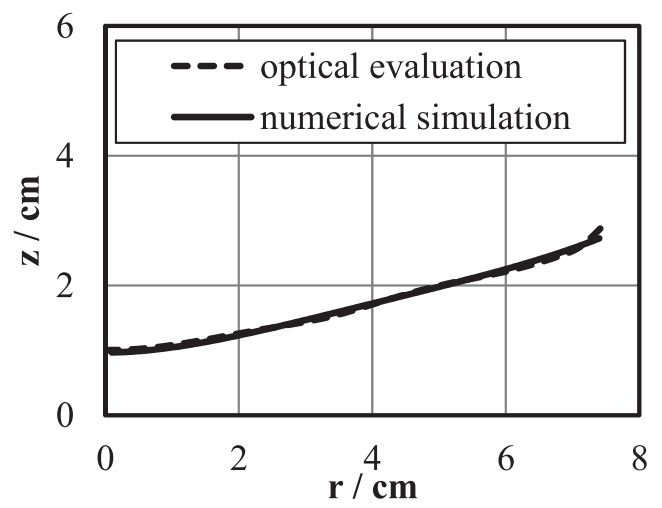

Case b

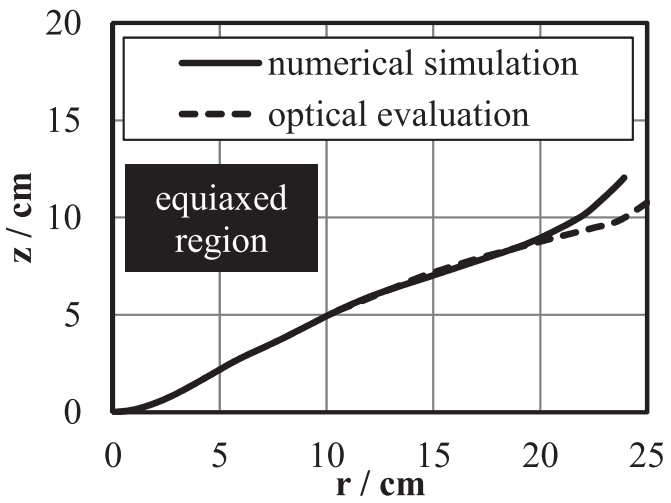

Fig. 9. Experimental und numerical pool profiles for both cases.

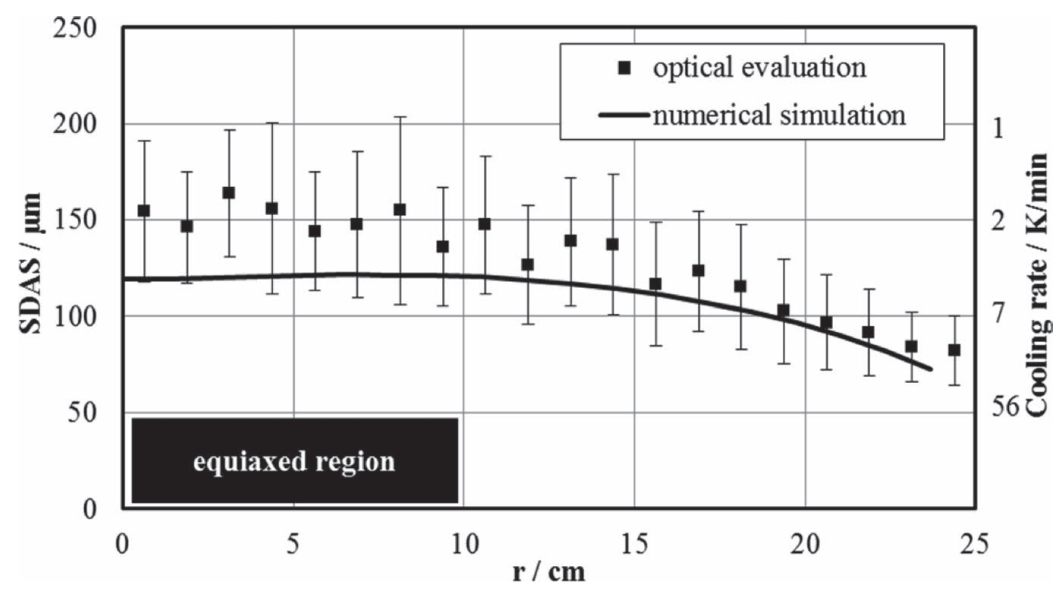

Fig. 10. Experimental und numerical SDAS and cooling rates during solidification. 
phase boundary's behavior. This formulation of the static phase boundary drastically reduces the time required until convergence is achieved.

The simulation model has been extensively validated by comparing the numerical results to experimentally gathered data for both the laboratory scale plant and the industrial scale remelting unit. The validation has been done considering the local solidification rate as well as the pool geometry.

\section{Acknowledgement}

The authors gratefully acknowledge the support of VDM Metals.

\section{Additional necessary equations:}

$$
\begin{gathered}
\mu_{\mathrm{t}}=\rho \mathrm{C}_{\mathrm{m}} \frac{\mathrm{k}^{2}}{\varepsilon} \\
\lambda_{\mathrm{t}}=\frac{\mathrm{c}_{\mathrm{p}} \cdot \mu_{\mathrm{t}}}{\operatorname{Pr}_{\mathrm{t}}} .
\end{gathered}
$$

$\mathrm{F}_{\mathrm{r}}$ : Volume specific radial force

$\mathrm{k}_{\mathrm{v}}$ : Volume specific production of $\mathrm{k}$

$\varepsilon_{\mathrm{v}}$ : Volume specific dissipation

$\mathrm{v}_{\mathrm{r}}$ : Radial velocity

$\lambda_{1}$ : Molecular thermal conductivity

$\lambda_{\mathrm{t}}$ : Turbulent thermal conductivity

$\sigma_{\mathrm{k}}$ : Turbulent Prandtl number for the turbulent kinetic energy

$\mu_{1}$ : Molecular dynamic viscosity

$\mu_{\mathrm{t}}$ : Turbulent dynamic viscosity $\sigma_{\varepsilon}:$ Turbulent Prandtl number for the dissipation

$\mathrm{C}_{\mathrm{m}}$ : Function of the realizable $\mathrm{k}-\varepsilon$ model

$\mathrm{c}_{\mathrm{p}}$ : Heat capacity

$\mathrm{Pr}_{\mathrm{t}}$ : Turbulent Prandtl number

\section{REFERENCES}

1) N. Giesselmann, A. Rückert and H. Pfeifer: Int. Conf. Simulation and Modelling of Metallurgical Processes in Steelmaking, Vol. 4, ASMET, Düsseldorf, (2011).

2) M. Choudhary and J. Szekely: Metall. Trans. B, 11 (1980), 439.

3) S. A. Cefalu, K. J. VanEvery and M. J. M. Krane: Proc. Multiphase Phenomena and CFD Modeling and Simulation in Materials Processing, TMS, Warrendale, PA, (2004), 279.

4) A. Jardy and D. Ablitzer: Mater. Sci. Technol., 25 (2009), 163.

5) A. Mitchell: Mater. Sci. Eng., 413-414 (2005), 10.

6) A. Mitchell: Int. J. Cast Metal. Res., 22 (2009), 216.

7) A. Mitchell: Mater. Sci. Technol., 25 (2009), 186.

8) A. Kharicha, A. Ludwig and M. Wu: STEELSIM, Int. Conf. Simulation and Modelling of Metallurgical Processes in Steelmaking, Vol. 4 , ASMET, Düsseldorf, (2011).

9) B. Hübner, E. Walhorn and D. Dinkler: Comput. Methods Appl. Mech. Eng., 193 (2004), 2087.

10) P. Masse, Y. Fautrelle and A. Gagnoud: IEEE Trans. Mag., 28 (1992), 1275.

11) D. Poirier: Metall. Mater. Trans. B, 18 (1987), 245.

12) G. Pottlacher, H. Hosaeus, E. Kaschnitz and A. Seifter: Scand. J. Metall., 31 (2002), 161.

13) J. Canny: IEEE Trans. Pattern Anal., 6 (1986), 679.

14) V. F. Leavers: CVGIP: Image Understanding, 58 (1993), 250

15) R. O. Duda and P. E. Hart: Commun. ACM, 15 (1972), 11.

16) S. Velastin and C. Xu: Image Feature Extraction Using a Method Derived from the Hough Transform with Extended Kalman Filtering: Advances in Image and Video Technology, Vol. 4872, ed. by D. Mery and L. Rueda, Springer, Berlin Heidelberg, (2007), 191.

17) L. Nastac, J. J. Valencia, M. L. Tims and F. R. Dax: Proc. Superalloys 718, 625, 706 and Various Derivatives, Minerals, Metals, and Materials Society, Warrendale, PA, (2001), 103. 